\title{
AUGMENTATION OF ANTIDEPRESSANTS WITH BRIGHT LIGHT THERAPY IN PATIENTS WITH COMORBID DEPRESSION AND BORDERLINE PERSONALITY DISORDER
}

\author{
Jan Prasko ${ }^{\mathrm{a}, \mathrm{b}, \mathrm{c}, \mathrm{d} *}$, Martin Brunovsky ${ }^{\mathrm{c}, \mathrm{d}}$, Klara Latalova ${ }^{\mathrm{a}, \mathrm{b}}$, Ales Grambala $^{\mathrm{a}, \mathrm{b}}$, Michal Raszka ${ }^{\mathrm{c}, \mathrm{d}}$, \\ Jana Vyskocilova ${ }^{\mathrm{c}}$, Lucie Zavesicka ${ }^{\mathrm{c}, \mathrm{d}}$
}

\author{
a Department of Psychiatry, University Hospital Olomouc, I. P. Pavlova 6, 77520 Olomouc, Czech Republic \\ b Psychiatry Clinic, Faculty of Medicine and Dentistry, Palacky University Olomouc \\ Prague Psychiatric Centre, Ustavni 91, Prague 8 \\ ${ }^{d}$ Centre of Neuropsychiatric Studies, Ustavni 91, Prague 8 \\ E-mail:prasko@fnol.cz
}

Received: March 15, 2010; Accepted: April 16, 2010

Key words: Bright light therapy/Non-seasonal depressive disorder/Depressive episode/Resistance to therapy/Borderline personality disorder/Comorbidity/Open study

Backround. Borderline personality disorder (BPD) is typically characterized by instability and impairmed behaviour, affectivity, interpersonal relations and lifestyle. The most common condition comorbid with BPD is a depressive episode. Depression is associated with severe disturbance of the circadian rhythms. This is apparent in depressive patients with BPD. Both sleep and diurnal rhythms are disturbed and the symptoms fluctuate. Bright light may be an effective in treatment of seasonal affective disorder, circadian sleep disorder and jet lag. It also improves sleep-wake patterns and behavioural disorders in hospitalized patients with Alzheimer's disease. Several studies have suggested antidepressant effects of phototherapy in non-seasonal depressive episodes. The treatment of comorbid depressive disorder and borderline personality disorder (BPD) is usually reported to be less successful than the treatment of patients without personality disorder. Studies describing the use of bright light in depressed patients with comorbid BPD have not been published so far.

Method. The aim of this open study was to assess the effectiveness of a 6-week combined therapy with the application of bright light (10,000 lux, 6:30 to 7:30 a.m. for 6 weeks) added to SSRIs in drug-resistant depressed patients with comorbid BPD who did not respond with improvement to 6-week administration of antidepressants. The study comprised 13 female patients who met the ICD-10 diagnostic criteria for research and the DSM-IV-TR diagnostic criteria for major depression. The participants were regularly evaluated using the CGI, HAMD and MADRS scales and the BDI and BDI self-report inventories.

Results. According to all the assessment instruments, the application of bright white light leads to a significant improvement. However, the results must be interpreted with caution due to the open nature of the study.

\section{INTRODUCTION}

Borderline personality disorder (BPD) is typically characterized by instability and impaired behaviour, affectivity, interpersonal relations and lifestyle. The condition is frequent, affecting about $2-3 \%$ of the general population. Persons with BPD account for approximately $10 \%$ of psychiatric outpatients, $15-20 \%$ of hospitalized psychiatric patients and $30-60 \%$ of all treated personality disorders ${ }^{1}$. Women are more affected than men (a ratio of $3: 1)$. In families, there is a higher prevalence of mood and personality disorder and dependence ${ }^{2}$. A core emotional feature of BPD is affective dysregulation, inability to delay gratification, albeit for a short time ${ }^{3}$. A good response to antidepressants and lithium ${ }^{4}$ and frequent depressive episodes led to considerations of a dysfunction of the serotonergic system ${ }^{5,6}$. According to these views, BPD may be classified as a type of affective disorder. However, it is unclear whether neurobiological findings are the cause, part or consequence of frequent interpersonal conflicts ${ }^{7}$. The disorder is usually associated with considerable stress and functional impairment. Most affected persons attempt to commit suicide repeatedly in the course of time. About $8-10 \%$ die of suicide which is 50 times higher than the general population. The risk of suicide is highest in adolescents and patients who develop affective disorder or become dependent on drugs $^{8}$. A combination of psychotherapy and pharmacotherapy is recommended. Treatment with psychoactive drugs is usually symptomatic, focused on the patients' symptoms ${ }^{9,10}$. The most common condition comorbid with BPD is a depressive episode. In this case, the effect of the two disorders is attenuated, depression is influenced by impulsive behaviour, self-harm is more frequent, conflicts with the others are more prominent and the risk of suicidal behaviour increases significantly. BPD patients suffer from emotional lability, increased sensitivity to rejection, inappropriate, intense anger, sudden depressive episodes and emotional outbursts. These symptoms, as well as depression itself, may be controlled by SSRIs or 
SNRIs ${ }^{8}$. This approach has been empirically supported by several studies ${ }^{4,11,12-16}$. The substances have a broad spectrum of therapeutic effects, are relatively safe in overdose and have tolerable adverse affects which is important for the patient's compliance. In acute treatment, SSRIs are administered for 6-14 weeks and then continuation therapy lasting for about 12 months is recommended. Some patients, however, continue to improve and stabilize their condition with 3 or more years of administration ${ }^{8}$. The dosage of antidepressants is recommended to be as high as in depression (e.g. fluoxetine $20-80 \mathrm{mg}$ /day, sertraline $100-200 \mathrm{mg} /$ day, venlafaxine up to $400 \mathrm{mg} /$ day) $\left(\right.$ ref. $\left.^{4}\right)$. However, antidepressant therapy may not be successful in more than $50 \%$ of patients, with little or no change in symptoms. It is unclear what step should follow in the treatment of these drug-resistant depressive patients with BPD. Depression is associated with severe disturbances of the circadian rhythms $\mathrm{s}^{17,18}$. This is also apparent in depressive patients with BPD. Both their sleep and their daily rhythms are disturbed and the symptoms fluctuate. Their lifestyle is generally dysrhythmic. These patients often stay up late and sleep during the day (mainly before noon but in fact at any time) because they feel exhausted. Their daily activities are chaotic and disorganized ${ }^{19}$. Yet their circadian rhythms have not been studied so far.

This study aimed at determining the effect of phototherapy added to the administration of SSRI in BPD patients suffering from chronic depressive episodes of a recurrent nature without the typical seasonal pattern.

\section{METHODS}

Included in the study were patients referred for the treatment of depressive episode and BPD at the Prague Psychiatric Centre, suffering from a depressive episode for at least 3 months and taking antidepressants in sufficient doses (equivalent to $40 \mathrm{mg}$ of paroxetine or higher) for at least 1.5 months (i.e. 3 months prior to phototherapy.
This was an open study which, in the case of positive results, is planned to be followed by a controlled blinded study.

While waiting for stay with specialized care, six weeks before the date of admission, patients were assessed for inclusion in the study (Table 1) using a diagnostic interview and the M.I.N.I. (Mini-International Neuropsychiatric Interview, Lecrubier et al. ${ }^{20}$ ). The severity of symptoms was evaluated according to the CGI (Clinical Global Impression) (ref. ${ }^{21}$ ), HAMD (21-item Hamilton Psychiatric Rating Scale for Depression) (ref. ${ }^{22}$ ) and MADRS (Montgomery and Åsberg Psychiatric Rating Scale for Depression) (ref. ${ }^{23}$ ) objective assessment scales. The patients completed the BDI (Beck Depression Inventory) (ref. ${ }^{24}$ ) and BAI (Beck Anxiety Inventory) $\left(\right.$ ref. ${ }^{25}$ ) self-report instruments. The assessments were repeated six weeks later. If there was no decrease in the HAMD score by at least $25 \%$ or an improvement in the CGI score by more than one point, bright light therapy $(10,000$ lux, 6:30 to 7:30 a.m. for 6 weeks $)$ was added without any changes in the medication ${ }^{17}$. Before initiation of phototherapy, all-night sleep EEG and actigraphy test of activity rhythms were carried out (the results will be published elsewhere). During the course of phototherapy, the level of psychopathology was assessed once a week with the CGI, HAMD and MADRS scales and BDI and BAI self-report inventories. After 6 weeks, phototherapy was discontinued, all-night sleep EEG was performed and daily rhythms were measured with actigraphs for 1 week. The last assessment of the level of psychopathology was carried out 2 weeks after phototherapy (Table 2).

Statistical analysis was done using the Prism 3 software. Both the demographic data and mean total scores in the individual assessment scales were evaluated using descriptive statistics to obtain the mean, standard deviation and data distribution patterns. Since distribution was normal in all the assessment scales used, the trends in the mean scores in individual assessment scales were deter-

Table 1. Study inclusion and exclusion criteria.

\begin{tabular}{|l|l|}
\hline \multicolumn{1}{|c|}{ STUDY INCLUSION CRITERIA } & \multicolumn{1}{c|}{ STUDY EXCLUSION CRITERIA } \\
\hline - Diagnosis of depressive episode according to the ICD- & - Meeting criteria for social phobia, panic disorder, \\
10 and DSM-IV-TR with M.I.N.I. & OCD, current or past bipolar disorder, current or past \\
- Diagnosis of emotionally unstable personality disorder & psychotic disorder, substance dependence \\
- borderline according to the ICD-10, and, and border- & - Mental retardation \\
line personality disorder according to the DSM-IV-TR & - A history of light-induced migraine \\
- Age over 18 years & - A HAMD decrease equal to or higher than 25\% during \\
- Depression lasting for at least 3 months & 6-week stable treatment \\
- For at least 1.5 months before inclusion into the study & - High suicidal risk suggested by history or M.I.N.I. \\
(i.e. 3 months before the initiation of phototherapy), & - Severe physical disease making pharmacotherapy of \\
the patients used antidepressants at a dose equivalent & phototherapy impossible \\
to or higher than 40 mg of paroxetine & - Severe agitation \\
- At least 16 points on the HAMD scale and a minimum & - Poor compliance \\
score of 4 on the CGI scale for inclusion in the photo- & - Patient not interested in participation \\
therapy phase & \\
- Patient's agreement with inclusion and signed in- & \\
formed consent & \\
\hline
\end{tabular}


Table 2. Time schedule of the study.

\begin{tabular}{|c|c|c|c|c|c|c|c|c|c|c|c|c|}
\hline Week -6 & -5 & -4 & -3 & -2 & Week -1 & Week 0 & 1 & \begin{tabular}{l|l|l}
2 & 3 & 4
\end{tabular} & 45 & Week 6 & 7 & Week 8 \\
\hline Screening & \multicolumn{5}{|c|}{$\begin{array}{l}\text { 6-week follow-up } \\
\text { at a constant dose of antidepressants }\end{array}$} & \multicolumn{4}{|c|}{$\begin{array}{c}\text { 6-week } \\
\text { phototherapy }\end{array}$} & $\begin{array}{c}\text { Completion } \\
\text { of photo- } \\
\text { therapy }\end{array}$ & & \\
\hline 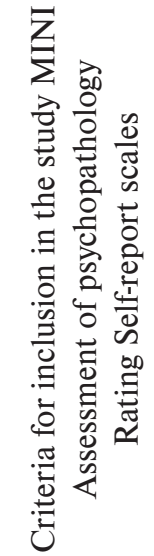 & & & & & 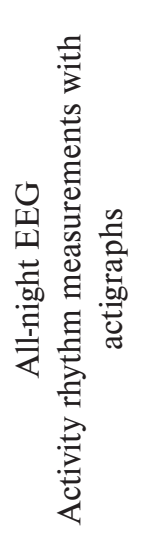 & 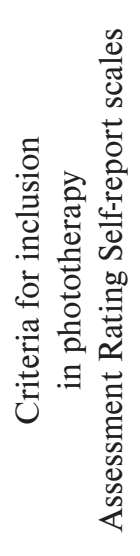 & & 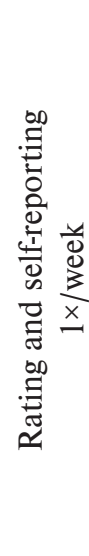 & & 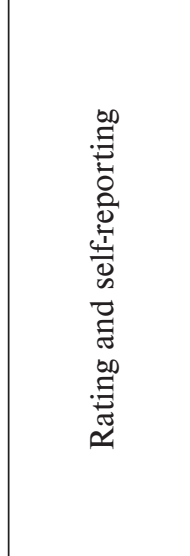 & 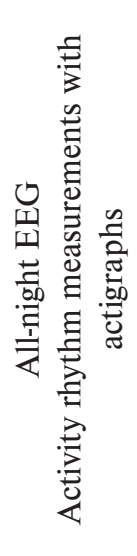 & 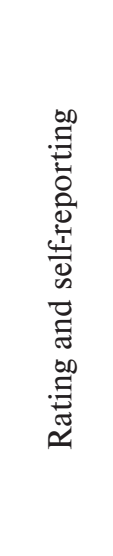 \\
\hline
\end{tabular}

mined using ANOVA for repeated measures with multiple comparison correction (Bonferroni adjustment). For all statistical evaluations, a level of statistical significance of $5 \%$ was considered acceptable. The study was approved by the local ethics committee.

\section{GROUP CHARACTERISTICS}

A total of 23 female patients diagnosed with depressive episode and BPD met the criteria for inclusion in the study and were willing to participate. Four patients were withdrawn during the first 6 weeks as their condition significantly improved and another 2 patients refused to attend the phototherapy sessions which in their opinion were too early in the morning. The phototherapy part of the study comprised 17 patients suffering from recurrent depressive disorder and borderline subtype of emotionally unstable personality disorder. One patient discontinued after 3 weeks as she felt much better and considered further therapy unnecessary. Thus, sixteen patients completed the study and their data were analysed.

None of the patients had the seasonal pattern of depression in the past. Their mean age was 33.50 \pm 7.983 years. The duration of their disease varied from 3 to 28 years, with a mean duration of $11.69 \pm 6.62$ years. The numbers of past depressive episodes were different in individual patients, ranging from 3 to 14 episodes. The mean duration of the current episode was $7.69 \pm 3.67$ months. Nine patients $(52.9 \%)$ harmed themselves at a mean rate of 1.41 per week; for the entire group, the mean self-harm rate was $1.5 \pm 2.01$. Self-harm behaviour was typical for younger patients; none of the patients over 32 years of age harmed themselves whereas all the younger ones did. All patients were taking SSRIs at a mean dose equivalent to paroxetine of $58.82 \pm 14.24 \mathrm{mg}$, a rather high dosage. Eleven patients $(64.71 \%)$ were taking adjunctive lamotrig- ine ( 6 patients), antipsychotics (6) and benzodiazepines (5). A total of 7 patients $(41.1 \%)$ were treated with a triple combination of drugs. Neither drugs nor their dosages changed markedly over the 6 weeks before phototherapy was initiated. At the beginning of the study (Week -6), the mean CGI level was $5.06 \pm 0.85$ points, corresponding to "markedly ill". In the participating patients, the severity slightly increased before phototherapy (Week 0: $5.19 \pm 0.66)$. Similarly, the mean scores in the HAMD $(24.63 \pm 5.28$ and $24.50 \pm 5.37$, respectively), MADRS $(28.13 \pm 8.22$ and $28.81 \pm 9.18$, respectively) and BDI self-rating instrument $(32.19 \pm 12.34$ and $30.05 \pm 12.60$, respectively) were in the ranges of severe depression. The BAI scale measuring the severity of self-reported anxiety showed moderate anxiety $(23.56 \pm 8.31$ and $23.50 \pm 6.90$, respectively). Thus, the mean severity of symptoms at the beginning was equal to severe depression and moderate anxiety (Table 3 ).

\section{ASSESSMENT OF THE THERAPY}

In the course of adjunctive phototherapy, the patients' scores in all assessment scales used improved significantly. Repeated measures analysis of variance showed a statistically highly significant decrease in symptoms over the time of the study. The mean CGI scores (severity of the disease) decreased from $5.188 \pm 0.655$ before the initiation of phototherapy (Week 0 ) to $2.688 \pm 0.947$ after its completion (Week 6) (ANOVA: $\mathrm{p}<0.0001, \mathrm{f}=44.86$, $\mathrm{r}=0.7494, \mathrm{df}=111)$. The Bonferroni multiple comparison test showed differences as early as between the beginning of the therapy and Week $1(\mathrm{p}<0.01)$ and between Week 1 and Week $2(p<0.001)$. The drops in the following weeks were not statistically significant.

The mean HAMD scores decreased from $24.50 \pm$ 5.367 at Week 0 to $10.94 \pm 5.721$ at Week 6 (ANOVA: 
Table 3. Mean scores and standard deviations in the course of therapy.

\begin{tabular}{|c|c|c|c|c|c|c|c|c|c|}
\hline scale & Week - 6 & Week 0 & Week 1 & Week 2 & Week 3 & Week 4 & Week 5 & Week 6 & Week 8 \\
\hline CGI & $\begin{array}{r}5.063 \\
\pm 0.8539\end{array}$ & $\begin{array}{r}5.188 \\
\pm 0.6551\end{array}$ & $\begin{array}{r}4.438 \\
\pm 1.031\end{array}$ & $\begin{array}{r}3.563 \\
\pm 1.153\end{array}$ & $\begin{array}{r}3.375 \\
\pm 1.204\end{array}$ & $\begin{array}{r}2.875 \\
\pm 0.9574\end{array}$ & $\begin{array}{r}2.625 \\
\pm 1.025\end{array}$ & $\begin{array}{r}2.688 \\
\pm 0.9465\end{array}$ & $\begin{array}{r}2.313 \\
\pm 1.078\end{array}$ \\
\hline HAMD & $\begin{array}{c}24.63 \\
\pm 5.277\end{array}$ & $\begin{array}{l}24.5 \\
\pm 5.367\end{array}$ & $\begin{array}{l}19.0 \\
\pm 8.359\end{array}$ & $\begin{array}{c}13.94 \\
\pm 6.846\end{array}$ & $\begin{array}{c}13.88 \\
\pm 7.438\end{array}$ & $\begin{array}{c}11.63 \\
\pm 6.407\end{array}$ & $\begin{aligned} & 9.75 \\
\pm & 6.148\end{aligned}$ & $\begin{array}{c}10.94 \\
\pm 5.721\end{array}$ & $\begin{array}{r}9.375 \\
\pm 5.702\end{array}$ \\
\hline MADRS & $\begin{array}{c}28.13 \\
\pm 8.221\end{array}$ & $\begin{array}{c}28.81 \\
\pm 9.181\end{array}$ & $\begin{array}{c}22.38 \\
\pm 9.946\end{array}$ & $\begin{array}{c}15.88 \\
\pm 8.601\end{array}$ & $\begin{array}{c}15.19 \\
\pm 8.264\end{array}$ & $\begin{array}{c}13.75 \\
\pm 7.047\end{array}$ & $\begin{array}{c}11.56 \\
\pm 7.229 \\
\end{array}$ & $\begin{array}{c}12.81 \\
\pm 7.139\end{array}$ & $\begin{array}{c}11.25 \\
\pm 7.416\end{array}$ \\
\hline BDI & $\begin{array}{r}32.19 \\
\pm 12.34\end{array}$ & $\begin{array}{r}30.5 \\
\pm 12.6\end{array}$ & $\begin{array}{r}25.31 \\
\pm 13.82\end{array}$ & $\begin{array}{r}23.25 \\
\pm 13.17\end{array}$ & $\begin{array}{r}23.56 \\
\pm 14.97\end{array}$ & $\begin{array}{r}22.56 \\
\pm 13.23\end{array}$ & $\begin{array}{r}19.56 \\
\pm 11.59\end{array}$ & $\begin{array}{r}18.75 \\
\pm 13.13\end{array}$ & $\begin{array}{r}16.88 \\
\pm 11.91\end{array}$ \\
\hline BAI & $\begin{array}{r}23.56 \\
\pm 8.31\end{array}$ & $\begin{array}{l}23.5 \\
\pm 6.899\end{array}$ & $\begin{array}{c}21.81 \\
\pm 7.679\end{array}$ & $\begin{array}{r}18.13 \\
\pm 10.95\end{array}$ & $\begin{array}{r}18.25 \\
\pm 12.36\end{array}$ & $\begin{array}{r}15.56 \\
\pm 9.77\end{array}$ & $\begin{array}{r}14.25 \\
\pm 8.888\end{array}$ & $\begin{array}{c}13.81 \\
\pm 8.697\end{array}$ & $\begin{array}{c}11.88 \\
\pm 8.648\end{array}$ \\
\hline $\begin{array}{l}\text { self-harm } \\
\text { rate/week }\end{array}$ & $\begin{aligned} & 1.5 \\
\pm & 2.033\end{aligned}$ & $\begin{array}{r}1.438 \\
\pm 1.548\end{array}$ & & & & & & 0 & $\begin{array}{c}0.25 \\
\pm 0.5774\end{array}$ \\
\hline
\end{tabular}

$\mathrm{p}<0.0001, \mathrm{f}=24.5, \mathrm{r}=0.620, \mathrm{df}=111)$. ). The Bonferroni multiple comparison test showed differences as early as between the beginning of the therapy and Week $1(\mathrm{p}<0.01)$ and between Week 1 and Week $2(p<0.01)$. The drops in the following weeks were not statistically significant.

The mean MADRS scores decreased from $28.81 \pm 9.18$ at Week 0 to $12.81 \pm 7.14$ at Week 6 (ANOVA: $p<0.0001$, $\mathrm{f}=20.86, \mathrm{r}=0.5817, \mathrm{df}=111)$. The Bonferroni multiple comparison test showed differences as early as between the beginning of the therapy and Week $1(p<0.05)$ and between Week 1 and Week $2(p<0.05)$. The drops in the following weeks were not statistically significant.

In the BDI subjective depression assessment scale, the mean scores decreased from $30.50 \pm 12.60$ at Week 0 to $18.75 \pm 13.13$ at Week 6 (ANOVA: $\mathrm{p}<0.0001, \mathrm{f}=6.310$, $\mathrm{r}=0.2961, \mathrm{df}=111$ ). Unlike objective assessment scales, the Bonferroni multiple comparison test only showed differences between Week 0 and Week $2(p<0.05)$.

In the BAI scale measuring the severity of self-reported anxiety, the mean scores decreased from $23.50 \pm 6.899$ at Week 0 to $13.81 \pm 8.697$ at Week 6 (ANOVA: $p<0.0001$, $\mathrm{f}=7.544, \mathrm{r}=0.3346, \mathrm{df}=111$ ). Unlike objective assessment scales, the Bonferroni multiple comparison test only showed differences between Week 0 and Week $4(p<0.05)$.

During the course of phototherapy, self-harm behaviour disappeared in all 9 patients previously harming themselves. However, two weeks after the completion of phototherapy, it reappeared in two patients, albeit with a low frequency.

\section{DISCUSSION}

The data suggest that a 6-week application of morning bright light therapy combined with administration of antidepressants could be an effective short-term augmentation strategy for BPD patients suffering from drugresistant non-seasonal depressive episodes. The results must be interpreted with caution since the study was open and comprised only a small number of patients. Most encouraging is the fact that bright light therapy in combination with antidepressants could help drug-resistant depressive patients with BPD. Highly significant decreases in symptoms were shown. However, the decreases were not as high as those reported in patients with seasonal affective disorder. It must be taken into account that patients in this group are frequently resistant to any form of treatment. The treated group of patients was resistant to previous antidepressant medication with sufficient dosages of antidepressants and with various augmentation strategies, such as the concomitant use of antiepileptics, benzodiazepines or antipsychotics. There were relatively long previous histories of depressive disorder. The question arises as to how effective bright light therapy would be in less chronic patients.

The placebo effect cannot be ruled out. Possible placebo effects of light therapy were described by Eastman ${ }^{26}$ in patients with seasonal affective disorder. There might be a strong placebo effect because of intensive treatment and assessment. Also the patients' regular daily regime may have an important therapeutic effect. Without a doubleblind experiment it is hard to tell which important factors would help the patients. On the other hand, these results may contribute to such a double-blind placebo-controlled experiment. It must also be considered that relatively high doses of antidepressant used for a long time might help some patients. Studies performed in obsessive-compulsive patients showed that in some patients, the effect of antidepressants may only be seen after as long as 6 weeks of standard treatment.

The overall decrease in symptoms may be also significantly influenced by social factors. The 1-hour session using a source of bright white light was usually simultaneously attended by 2-3 patients who spent the time talking to each other. Without a placebo-controlled experiment with independently assessed effects it is impossible to state whether the fall in scores in individual objective and subjective assessment scales resulted from the effect of 


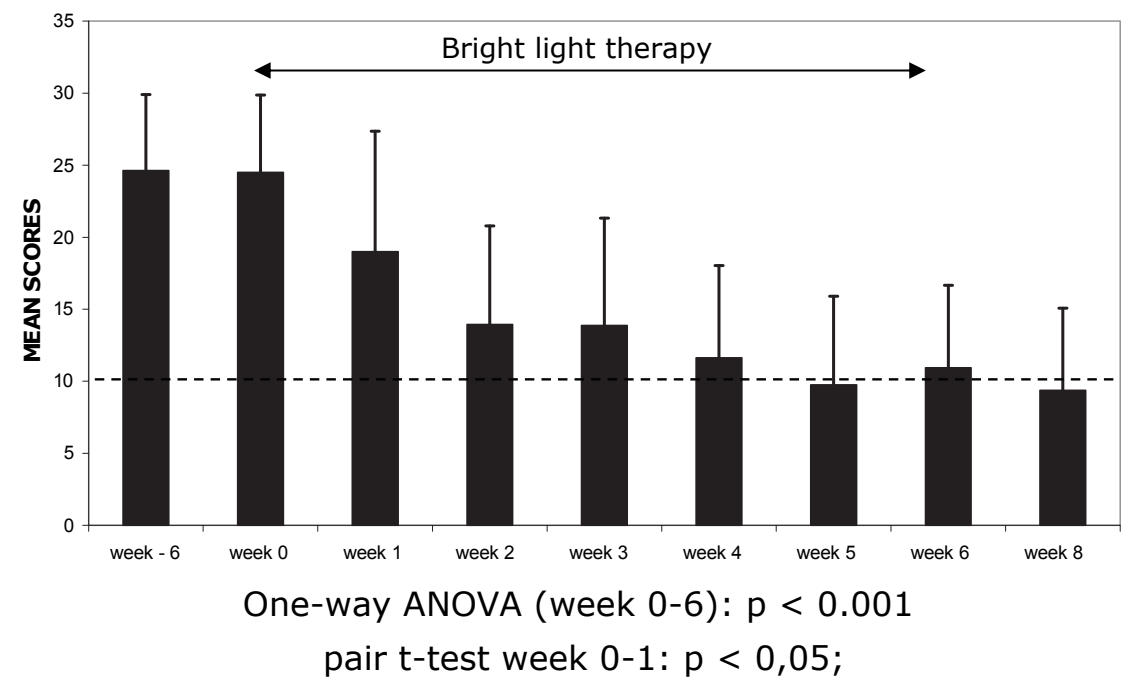

Fig. 1. Hamilton rating scale for depression.

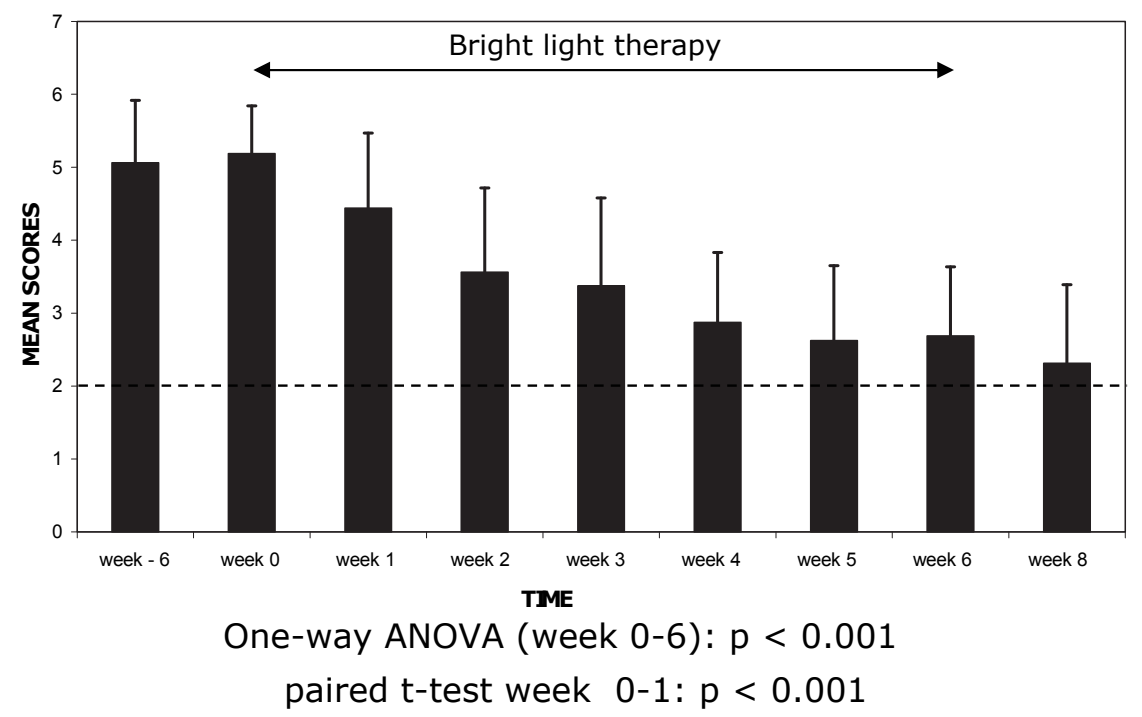

Fig. 2. Clinical global impression.

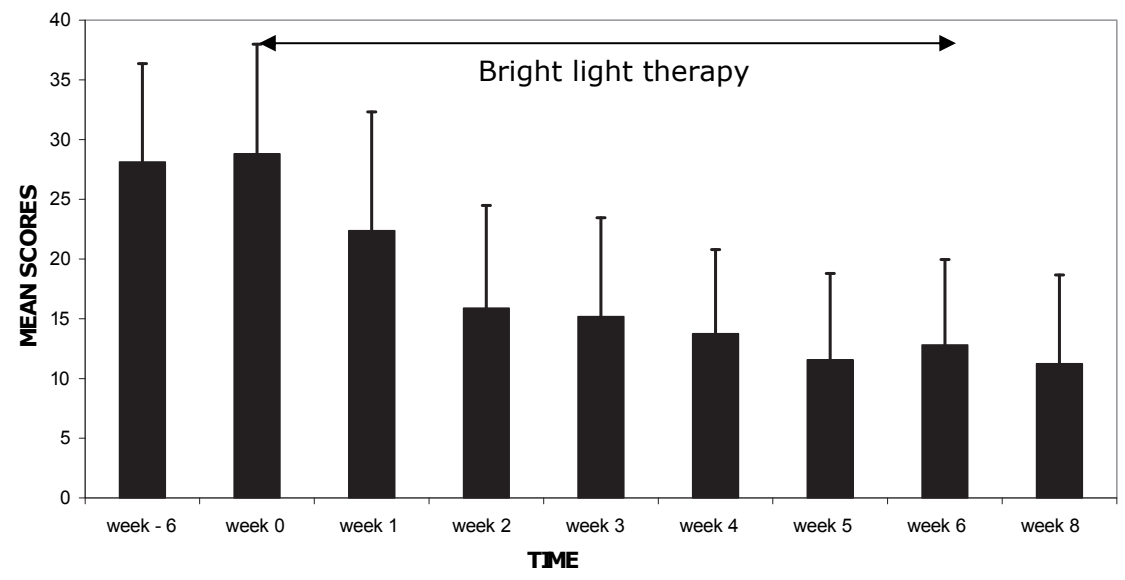

One-way ANOVA (week 0-6): $p<0.001$

paired t-test week $0-1: p<0.05$

Fig. 3. Montgomery and Asberg rating scale for depression. 


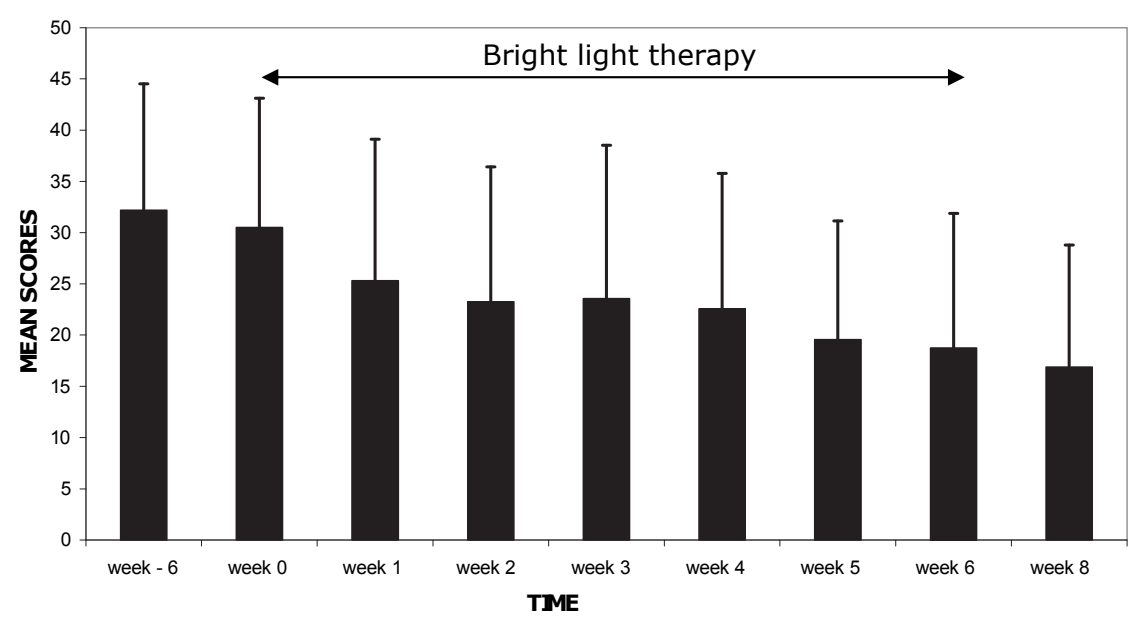

One-way ANOVA (week 0-6): $\mathrm{p}<0.001$

paired t-test week 0-1: n.s.; week 0-2: $p<0.005$

Fig. 4. Beck depression inventory.

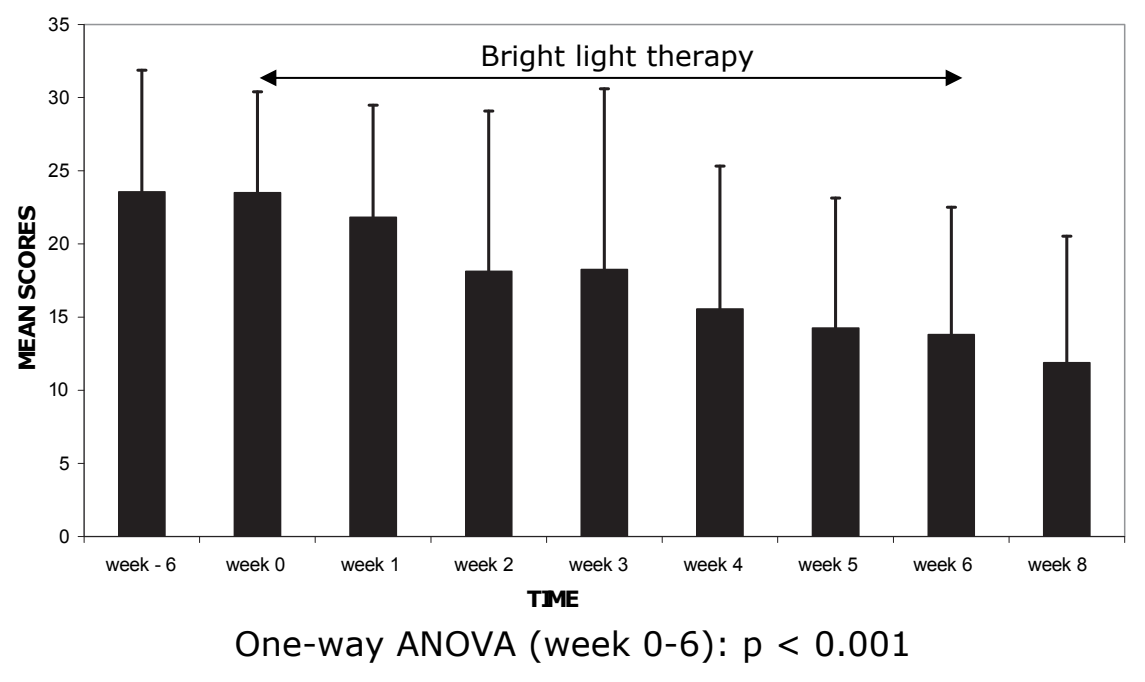

paired t-test: week 0-1: n.s.; week 0-2: $p<0.05$

Fig. 5. Beck anxiety inventory.

bright light or from other, non-specific, factors including expectations of the raters.

Interestingly, when the HAMD primary instrument for assessing the severity of depression was used, $56.3 \%$ of patients achieved better outcomes, when compared with $44.8 \%$ of patients who achieved values of 1 or 2 in CGI, a scale for assessing the overall status by a clinician. The discrepancy may be explained by comorbid conditions. In BPD patients, a significant improvement in severity of depression may not mean a significant overall improvement since certain features are not detectable by the HAMD, such as self-harm, impulsive and explosive behaviour, feeling of inner emptiness or boredom etc.

Another question is whether combined therapy is necessarily beneficial in depressive patients with BPD and whether bright light monotherapy would not be more effective. The question cannot be answered without an experiment to verify this.

\section{CONCLUSION}

In conclusion, drug-resistant depression with BPD is associated with a significant personal, social and economic burden. New strategies for its clinical management should be searched. For this purpose, the addition of bright light therapy to continued administration of antidepressants seems useful. The results advocate the use of bright light treatment as an adjunct therapy for non-seasonal depression in patients suffering from borderline personality disorder. Future studies should focus on exploring the efficacy of light therapy in this comorbidity under double-blind conditions.

\section{AKNOWLEDGEMENT}

This paper was supported by CNS MSMT CR 1M0517. 


\section{REFERENCES}

1. Phillips KA and Gunderson JG. Personality disorders, in The American Psychiatric Press Textbook of Psychiatry, 3rd ed. Edited by Hales RE, Yudofsky SC, Talbott JA. American Psychiatric Press, Washington DC 1999; 795-823.

2. Corbitt EM and Widiger TA. Sex differences among the personality disorder. An exploration of the data. Clin Psychol Sci Pract 1995; 2:225-238.

3. Linehan MM and Kehrer CA. Borderline personality disorder. In: Barlow, D.H. (ed.): Clinical handbook of psychological disorders. A step-by-step treatment manual. The Guilford Press, New York 1993; 396-441.

4. Markowitz P. Pharmacotherapy of impulsivity, aggression, and related disorders, in Impulsivity and Aggression. Edited by Hollander E, Stein DJ. New York, John Wiley \& Sons 1995; 263-287.

5. Siever LJ. Evaluation framework for biological correlates of personality disorder. Psychiatr Times 1990; 7:17-19.

6. Silk KR. Borderline personality disorder. Overview of biological factors. Psychiatr Clin N Am 2000; 23:61-75.

7. Gunderson JG. Borderline Personality Disorder: A Clinical Guide American Psychiatric Press, Washington DC 2001.

8. American Psychiatric Association: Practice Guidelines for the Treatment of Patients with Borderline Personality Disorder Washington, DC, APA 2001.

9. Markowitz P. Pharmacotherapy. In: Livesley WJ (ed): Handbook of Personality Disorders. Guilford Press, New York 2001; 475-493.

10. Praško J, Herman E, Horáček J et al. Poruchy osobnosti. Praha: Portál 2003; 360p.

11. Salzman C, Wolfson AN, Schatzberg A, Looper J, Henke R, Albanese M, Schwartz J, Miyawaki E. Effect of fluoxetine on anger in symptomatic volunteers with borderline personality disorder. J Clin Psychopharmacol 1995; 15:23-29.12. Markowitz PJ, Calabrese JR, Charles SC, Meltzer HY. Fluoxetine in the treatment of borderline and schizotypal personality disorders. Am J Psychiatry 1991; 148:1064-1067.
13. Markowitz PJ and Wagner C. Venlafaxine in the treatment of borderline personality disorder. Psychopharmacol Bull 1995; 31:773777.

14. Cornelius JR, Soloff PH, Perel JM et al. Fluoxetine trial in borderline personality disorder. Psychopharmacol Bull 1990; 26:151-154.

15. Kavoussi RJ, Liu J, Coccaro EF. An open trial of sertraline in personality disordered patients with impulsive aggression. J Clin Psychiatry 1994; 55:137-141.

16. Norden MJ. Fluoxetine in borderline personality disorder. Prog Neuropsychopharmacol Biol Psychiatry 1989; 13:885-893.

17. Praško J, Horáček J, Klaschka J et al. Bright light therapy and/or imipramine for inpatients with recurrent non seasonal depression. Neuro Endocrinol Lett 2002; 23:109-113.

18. Illnerová H, Borbély AA, Wirz-Justice A, Praško J. Circadian rhythmicity: from basic science to clinical approach. Suppl Clin Neurophysiol 2000; 53:339-347.

19. Praško J, Houbová P, Novák T, Záleský R, Espa-Červená K, Pašková B, Vyskočilová J. Influence of personality disorder on the treatment of panic disorder - comparison study. Neuro Endocrinol Lett 2005; 26:667-674.

20. Lecrubier Y, Sheehan DV, Weiller E et al. The MINI-international neuropsychiatric interview (M.I.N.I.): a short diagnostic structured interview: reliability and validity according to the CIDI. Eur Psychiatry 1997; 12:224-231.

21. Guy W (ed.). ECDEU Assessment manual for psychopharmacology. Rockville, U.S. DHEW 1976.

22. Hamilton M. Development of a Rating Scale for Primary Depressive Illness. Brit J Soc Clin Psychol 1967; 6:278-296.

23. Montgomery SA, Asberg M. A New Depression Scale Designed to be Sensitive to Change. Brit J Psychiatry 1979; 134:382-389.

24. Beck AT and Beamesderfer A. Assessment of Depression: The Depression Inventory. In: Psychological Measurements in Psychopharmacology 1974; 7:151-169.

25. Beck AT and Emery G. Anxiety disorders and phobias: A cognitive perspective. New York, Basic Books 1985.

26. Eastman C. What the placebo literature can tell us about phototherapy for SAD. Psychopharmacol Bull 1990; 26:495-504. 
